\title{
No limite da razão: o deliberar e a phrónesis no trabalho prisional
}

\author{
DÉRIS Oliveira CaItano ${ }^{1}$ \\ MAURÍ́cIO SERVA ${ }^{12}$ \\ 1 Universidade Federal de Santa Catarina (UFSC) / Núcleo de Pesquisa em Organizações, Racionalidade e DeSenVolvimento, \\ FLORIANÓPOLIS - SC, BRASIL

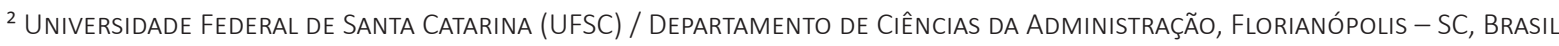

\section{Resumo}

Este estudo teve por objetivo verificar na experiência dos agentes penitenciários, em um complexo prisional de segurança máxima, elementos que caracterizem um quadro de evidências da phrónesis. A phrónesis foi descrita na filosofia aristotélica como a virtude de ordem prática que pressupõe o deliberar em situações críticas, onde a racionalidade dos agentes é limitada por contextos muito específicos de ação. A noção de phrónesis ilumina novas perspectivas para compreender a racionalidade em circunstâncias contingenciais da práxis organizacional. Trata-se de pesquisa empreendida a partir de uma análise microssociológica das práticas dos agentes no trabalho prisional. Os dados foram coletados por meio de entrevistas e triangulados com observação em campo e análise de documentos. Os resultados desta pesquisa ilustram evidências da phrónesis a partir da análise da experiência dos agentes na contenção de ações do crime organizado no interior do complexo prisional e nos efeitos produzidos na gestão com base nessa experiência.

Palavras-chave: Phrónesis. Racionalidade. Pragmatismo. Agente penitenciário.

\section{The limits of reason: deliberation and phronesis of correctional officers}

\begin{abstract}
The objective of this article was to verify in the experience of correctional officers, in a maximum security prison complex, elements that characterize a framework of phrónesis evidence. Phrónesis was described in Aristotelian philosophy as the virtue of a practical order that presupposes deliberation in critical situations, where the rationality of agents is limited by very specific contexts of action. The notion of phrónesis clear new perspectives to understand rationality in contingent circumstances of organizational praxis. This research was undertaken from a micro-sociological analysis of the practices of the agents in prison work. Data were collected from interviews and triangulated with field observation and document analysis. The results of the research illustrate evidence of the phrónesis from the analysis of the experience of the agents in the containment of organized crime actions inside the complex and in the effects produced in the management from that experience.
\end{abstract}

Keywords: Phrónesis. Rationality. Pragmatism. Penitentiary Agents.

\section{Al límite de la razón: deliberación y frónesis en el trabajo de agentes penitenciarias}

\section{Resumen}

Este artículo tuvo por objetivo verificar en la experiencia de los agentes penitenciarios, en un complejo carcelario de seguridad máxima, elementos que caracterizan un cuadro de evidencias de la frónesis. La frónesis fue descrita en la filosofía aristotélica como la virtud de orden práctico que presupone el deliberar en situaciones críticas, donde la racionalidad de los agentes está limitada por contextos muy específicos de acción. La noción de frónesis ilumina nuevas perspectivas para comprender la racionalidad en circunstancias contingenciales de la praxis organizacional. Se trata de una investigación emprendida a partir de un análisis microsociológico de las prácticas de los agentes en el trabajo carcelario. Los datos fueron recolectados a partir de entrevistas y triangulados con observación en campo y análisis de documentos. Los resultados de la investigación ilustran evidencias de la frónesis a partir del análisis de la experiencia de los agentes en la contención de acciones del crimen organizado en el interior del complejo carcelario y en los efectos producidos en la gestión a partir de esa experiencia.

Palabras clave: Frónesis. Racionalidad. Pragmatismo. Agente penitenciario. 


\section{INTRODUÇÃO}

No Brasil, o crescimento da criminalidade resultou nos últimos anos em um aumento da população encarcerada e, consequentemente, em maior déficit de vagas no sistema prisional (LIMA e BUENO, 2015) ${ }^{1}$. A superlotação e o descaso com a gestão das unidades prisionais, especialmente nos grandes centros urbanos, favoreceram a proliferação de grupos criminosos organizados (facções) e com poder de atuação dentro e fora das prisões (SALLA, 2006; ADORNO, 2008; DIAS, 2011; RANGEL e BICALHO, 2016).

A relação entre os problemas de segurança pública e o que ocorre efetivamente dentro das prisões ultrapassa a perspectiva legal e requer a adoção de alternativas que viabilizem a capacidade de gestão dessas organizações, como uma condição determinante na contenção e no rastreamento das ações do crime organizado. Todavia, poucos estudos têm proposto a investigação de temas relacionados à gestão e ao trabalho nas prisões sob a perspectiva dos agentes penitenciários.

A maior parte da produção científica sobre esse tema enfatiza perspectivas teóricas voltadas às inquietações e aos dilemas do sujeito preso. No que toca à gestão e ao trabalho nas prisões, cabe mencionar a contribuição dos estudos no campo da sociologia: Adorno (2002), Salla (2006), Nunes Dias (2011), Bodê de Moraes (2013), Manso e Dias (2017). E no campo da gestão temos os estudos de: Freitas (1985), Lemos, Mazzilli e Klering (1998), Cabral e Lazzarini (2010), Cruz, Souza e Batitucci (2013) e Rangel e Bicalho (2016).

Neste estudo, presumimos que qualquer tentativa de reproduzir um modelo de gestão que oriente as ações de segurança pública no sentido de conter os avanços do crime organizado (dentro e fora das prisões) não produzirá os mesmos efeitos em contextos distintos de ação (local ou regional). Essa incapacidade preditiva e normativa da gestão abarcar todos os fenômenos relacionados às sutilezas do conteúdo humano é o que configura o caráter essencialmente contingencial do trabalho nas prisões (BODÊ DE MORAES, 2005; GOFFMAN, 2008).

Consideramos que a capacidade de gestão, especialmente nesse universo organizacional, está atrelada ao contexto específico de ação e limitada em sua racionalidade pela profundidade e pela incerteza de um contexto irredutível às regras (CLEGG, 2003, 2006). Esse limite da racionalidade sob a qual se constitui a teoria organizacional é o que caracteriza a gestão como um exemplo de phrónesis (CLEGG, 2003; FLYVBJERG, 2001, 2006).

No atual estágio do campo de estudos da racionalidade nas organizações, após os estudos fundamentais de Guerreiro Ramos (1989), interessa aprofundar o conhecimento da racionalidade em ação, particularmente intensificando as pesquisas empíricas que abordem o tema da racionalidade sob a perspectiva da ação nas organizações, pondo ênfase e problematizando as práticas de gestão. Entendemos que essa é a linha de pesquisa que propiciará o avanço desse campo científico e trará uma contribuição efetiva à administração, que é, por definição, uma ciência social aplicada. Para tanto, empregamos o conceito de phrónesis evitando a discussão abstrata e meramente conceitual sobre a racionalidade ao privilegiar sua dimensão prática. Nesse sentido, em nossa pesquisa, a correspondência entre a filosofia e a administração é estabelecida por meio de uma filosofia como epistemologia da prática elaborada sob a égide do pragmatismo (FREGA, 2006, 2012).

A phrónesis (concebida como sabedoria prática ou prudência) é descrita na filosofia de Aristóteles (1991) como virtude intelectual de ordem prática capaz de auxiliar o homem a tomar a melhor decisão em cada contexto. Para Aubenque (2008) e Maclntyre (1991), a phrónesis envolve a capacidade do agente deliberar sobre o fator contextual, que é variável, contingente e pertence ao campo da prática como o sujeito age efetivamente orientado por suas razões.

O aspecto contextual difere da universalidade dos casos que caracteriza o paradigma de ciência vigente, por isso, a phrónesis representa uma alternativa para a compreensão dos fenômenos no campo do social (FLYVBJERG, 2001, 2006); no campo da gestão (KOIKE e MATTOS, 2001; CLEGG, 2003; KARAM, 2014; SANTOS, SERAFIM, PINHEIRO et al., 2018) ou, ainda, para a compreensão do que Champy (2018) e Dubois (2018) descreveram como atividades "prudenciais" relacionadas a contextos muito específicos de ação, como no caso dos hospitais e das prisões. No âmago desse conceito se encontra a capacidade do agente de deliberar em uma zona de incerteza, onde não há conhecimento técnico e científico disponível (FLYVBJERG, 2001, 2006; DUBOIS, 2018).

\footnotetext{
${ }^{1}$ Até o ano de 2030, o Brasil poderá alcançar uma população prisional de 1,9 milhão de presos adultos, o que demandaria a construção de 5.780 unidades prisionais em 15 anos (FBSP, 2015).
} 
Sem lograr compreender todo o campo de gestão que envolve o sistema penitenciário, o que se propõe aqui é uma análise pragmatista sobre as práticas de gestão dos agentes penitenciários diante de situações contingenciais. $O$ recorte da pesquisa incide sobre o Complexo Penitenciário de Segurança Máxima de São Pedro de Alcântara (COPE), o maior do Estado de Santa Catarina, o qual se destacou no cenário nacional por uma série de eventos críticos nos anos de 2012, 2013 e 2014 e por ter se tornado referência em algumas práticas de gestão no sistema penitenciário nacional.

Dessa forma, inspirados no conceito aristotélico de phrónesis e considerando o trabalho nas unidades prisionais uma atividade complexa, este estudo se propõe a verificar a seguinte questão:

- As práticas de determinados agentes penitenciários em situações críticas de gestão, onde o agente é chamado a deliberar sobre demandas contingenciais, constitui um quadro de evidências da phrónesis?

Partiu-se do pressuposto de que o trabalho nas unidades prisionais remete a inúmeras práticas e fenômenos que colocam em evidência a escolha e o deliberar diante de eventos contingenciais. Esses elementos corporificam de modo mais expressivo os limites da racionalidade em situações inusitadas (CLEGG, 2003), compondo um quadro de evidências da phrónesis.

A perspectiva é que a compreensão da phrónesis permita transitar no debate teórico dos estudos da racionalidade (GUERREIRO RAMOS, 1989; SERVA, 1997a; SERVA, CAITANO, SANTOS et al., 2015) pela órbita subjetiva para a verificação das práticas. Tal transição para a ação é conduzida a partir dos elementos da sociologia pragmatista, adotada neste estudo enquanto recurso metodológico e analítico de investigação (DODIER, 2005; BOLTANSKI e THÉVENOT, 2006; CEFAï, 2009).

\section{O PONTO DE PARTIDA ANALÍTICO: ESTUDOS DA RACIONALIDADE}

A investigação da phrónesis adotada neste estudo se integra a uma trajetória de estudos da racionalidade nas organizações, baseado nas discussões de Guerreiro Ramos (1989) e Serva (1997a, 1997b). A análise desses estudos no Brasil, elaborada por Serva, Caitano, Santos et al. (2015), validou as proposições sobre a coexistência de diferentes racionalidades na gestão de organizações, considerando a lógica de ação instrumental e a lógica de ação substantiva. Flyvbjerg (2003, p. 358, tradução nossa) propõe a phrónesis como o dispositivo de ação que permite ao indivíduo agir e deliberar a partir de distintas lógicas racionais, de acordo com a situação:

Aristóteles era explícito em relação à phrónesis como a mais importante das três virtudes intelectuais: episteme, techne e phrónesis. A phrónesis é mais importante porque é aquela atividade pela qual a racionalidade instrumental é equilibrada por racionalidade de valor, usando os termos do sociólogo alemão Max Weber.

A phrónesis enquanto capacidade superior à própria razão é assinalada por Aristóteles (1991, p. 145):

A sabedoria prática deve, pois, ser uma capacidade verdadeira e raciocinada de agir com respeito aos bens humanos [...] Sem embargo, ela é mais que uma simples disposição racional: mostra o fato de que tais disposições podem ser esquecidas, mas a sabedoria prática, não.

Nas correntes pragmatistas da sociologia francesa, os autores recuperam o conceito de phrónesis para explicar a forma como os agentes elaboram suas justificações diante das controvérsias. Inicialmente, na abordagem das justificações de Boltanski e Thévenot (2006), a phrónesis é o princípio superior, abstraído da noção de bem comum da filosofia aristotélica que permite aos atores em momentos de disputas e controvérsias agir a partir de diferentes lógicas de argumentação e entender qual ação esperada pode produzir um estado de bem comum para todos.

O embasamento no pragmatismo permite elaborar uma proposição do lugar da razão nos assuntos humanos e como os agentes recorrem a ela para se engajar em suas interações (FREGA, 2012). Nesse sentido, o pragmatismo retira a abordagem da racionalidade do risco de recair nas abstrações transcendentais, valorizando a dimensão autorreflexiva de experiências e ações. A racionalidade nos estudos pragmatistas está na forma como os atores elaboram a crítica de suas próprias experiências, situando-se na base da capacidade, no controle e na justificação de suas ações (FREGA, 2012; FREGA, 2006). A phrónesis se encontra, portanto, na capacidade dos agentes deliberarem suas ações a partir de propósitos referentes ao bem comum. 


\section{A phrónesis aristotélica}

Phrónesis, do verbo phroneo, designa em geral a ação de pensar, ter bom senso, prudência, sabedoria. Aristóteles (1991) retoma dos gregos pré-socráticos o conceito de phrónesis que se torna central em suas discussões sobre ética e ação humana (AUBENQUE, 2008). A ênfase aristotélica nas virtudes como o cerne da vida moral foi desconsiderada na modernidade e retomada nos últimos 40 anos, quando numerosos trabalhos enriqueceram as reflexões sobre o conceito de prudência. Influenciados especialmente por Martin Heidegger, autores contemporâneos, como Hans-Georg Gadamer, Hannah Arendt, Paul Ricouer orientaram parte da discussão de seus temas com base no conceito de phrónesis (FLYVBJERG, 2001, 2006; AUBENQUE, 2008).

Em Aristóteles (1991), a sabedoria prática (phrónesis) corresponde a uma das virtudes da alma, assim como a arte (techne), o conhecimento científico (episteme), a sabedoria filosófica (sophia) e a razão intuitiva (nous). A phrónesis (prudência) é definida por Aristóteles (1991) como uma virtude intelectual do homem prático, capaz de auxiliá-lo a tomar a melhor decisão em cada contexto. Tal virtude se ocupa do que é particular, variável, por isso distinto do conhecimento científico, o qual está relacionado ao que é universal e invariável (MACINTYRE, 1991). Difere do conhecimento científico a partir do objeto de deliberação, "mas não delibera sobre coisas necessárias ou imutáveis, pois estas são objeto da ciência, a sabedoria prática seria a virtude de deliberar sobre o que é contingente, sobre aquilo que não é objeto de ciência" (AUBENQUE, 2008, p. 64).

Aristóteles (1991) faz uma clara distinção entre as três formas possíveis de conhecimento em sua filosofia (Quadro 1).

Quadro 1

Formas do conhecimento

\begin{tabular}{|l|l|c|}
\hline FORMA DE CONHECIMENTO & \multicolumn{1}{|c|}{ DEFINIÇÃO } & ATIVIDADE \\
\hline EPISTEME & $\begin{array}{l}\text { Conhecimento fruto da observação com a intenção de } \\
\text { aprender. } \\
\text { Conhecimento científico }\end{array}$ & TEORIA \\
\hline TECHNE & $\begin{array}{l}\text { Atividade produtiva voltada à fabricação de artefatos e } \\
\text { utensílios. } \\
\text { Racionalidade prática e instrumental. }\end{array}$ & POIESIS \\
\hline PHRÓNESIS & $\begin{array}{l}\text { Determina em cada caso o modo adequado de } \\
\text { comportamento em situações concretas e reais da vida. } \\
\text { Saber situacração sobre valores. }\end{array}$ & PRÁXIS \\
\hline
\end{tabular}

Fonte: Adaptado de Escudero (2011) e Flyvbjerg $(2003,2006)$.

A distinção entre o conhecimento científico (episteme) e a phrónesis acende um debate sobre o lugar das ciências sociais nesse enclave. Tal debate é empreendido por autores como Flyvbjerg $(1998,2001,2003)$, que propõe o resgate da phrónesis como um paradigma de pesquisa nas ciências sociais. Para esse autor, as noções de contingência e de contexto são frequentemente ofuscadas pelo paradigma de ciência e o imperativo de universalidade dos casos, todavia, esses elementos são requisitos fundamentais para a compreensão dos fenômenos sociais e isso inclui a gestão. Uma proposição semelhante foi destacada por Koike e Mattos (2001), que questionam a forma como o conhecimento na teoria administrativa considerou apenas a episteme enquanto paradigma de conhecimento válido e o que levou à perda da ideia de phrónesis no nível do discurso erudito.

Inspirado nos argumentos de Flyvbjerg $(2001,2003)$, Clegg $(2003$, p. 1, tradução nossa) sugere a phrónesis como o elemento capaz de retirar os estudos organizacionais das limitações do campo da racionalidade: "uma proposição central dos estudos organizacionais é que a tomada de decisão sempre é limitada em sua racionalidade pelas grandes profundidades e pelos confins da incerteza e da ignorância sobre a qual sempre estará constituída". Para o autor, por ser uma ciência de sujeitos, a teoria organizacional só pode ser compreendida a partir de contextos específicos de ação, o que caracterizaria a teoria organizacional como um exemplo de phrónesis (CLEGG, 2006). 
Para compreender o contexto e as situações como um dos elementos da phrónesis, recorremos à análise das situações de gestão proposta por Girin $(1996,2011)$, bem como à análise pragmatista da ação baseada em situações conforme discutida por Quéré (1997). Esses autores apresentam uma perspectiva de análise de fenômenos sociais a partir da consideração da centralidade da ação, levando em conta os trabalhos de Goffman $(2001,2008)$, que incluem o universo das prisões.

Em Aubenque (2008), um dos intérpretes de Aristóteles (1991), encontramos uma compreensão da phrónesis a partir de uma reflexão vertical da obra, no que o autor identifica como antropologia e cosmologia dos elementos constituintes da phrónesis: o homem prudente (phronimos), a contingência do mundo, o tempo oportuno (kairós), o deliberar, a escolha. Na leitura de Aubenque (2008), a phrónesis está relacionada à contingência do mundo, à ideia de um mundo inacabado, por isso se trata de uma virtude situacional. Assim, diante de circunstâncias variáveis e não previsíveis, o homem prudente delibera sua ação considerando a noção de tempo oportuno e o contexto relacionado. A síntese dos elementos da phrónesis aristotélica interpretada por Aubenque (2008) oferece alguns elementos norteadores para empreendermos a análise do objeto de estudo aqui considerado.

\section{METODOLOGIA}

Esta pesquisa assume um caráter qualitativo com abordagem de estudo de caso no COPE. A investigação foi realizada a partir de um corte seccional e longitudinal e o levantamento dos dados foi empreendido por trajetórias distintas: a) observação das práticas na organização; b) entrevistas em profundidade; e c) análise documental.

A primeira trajetória compreendeu a observação das práticas, tomando por referência uma visão bottom-up da microssociologia pragmatista (VANDENBERGUE, 2006; CEFAï, 2009). Trata-se de uma investigação de corte seccional, realizada em 5 oportunidades, entre janeiro e março de 2016. As incursões no campo foram limitadas às condições operacionais da unidade de oferecer visitas acompanhadas por agentes; nessas oportunidades foram realizadas observações in loco dos diferentes espaços e em diferentes plantões. Além da observação e dos questionamentos aos plantonistas, registraram-se imagens (fotos) para auxiliar a elaboração da análise.

Uma segunda etapa que contribuiu para a compreensão do fenômeno, do histórico da organização e das mudanças nas práticas foi o levantamento e a análise de dados secundários, provenientes de documentos internos, dos registros de denúncias realizadas no Ministério Público (MP), dos processos criminais, das notícias divulgadas na mídia local e nacional. Essas informações proveem subsídios para compreender os relatos das entrevistas que remetem, com frequência, ao período de crise instaurado entre 2011 e 2014.

A narrativa da experiência vivenciada pelos agentes diante das crises relacionadas ao COPE foi levantada por meio de entrevistas semiestruturadas, realizadas com 15 agentes penitenciários que atuaram na unidade no período do estudo. Entre os entrevistados havia 3 agentes que estiveram à frente da gestão do COPE entre 2010 e 2016.

Os dados provenientes da observação das práticas foram triangulados com as entrevistas e a análise de documentos. Nesse sentido, os três níveis de análise foram trabalhados e integrados: a) o nível macro pela análise dos momentos críticos do contexto; b) o nível meso com base na observação e análise das ações na organização; e c) o nível micro representado pela reflexão sobre a experiência vivenciada especificamente pelos agentes.

A phrónesis foi investigada a partir das seguintes evidências: a) eventos contingenciais; b) tempo da ação; e c) deliberação. Esses elementos são destacados no decorrer da análise dos dados e compõem uma síntese que engendra a conclusão desta pesquisa. 


\section{ANÁLISE DOS DADOS: A ORGANIZAÇÃO E SUAS PRÁTICAS}

O COPE foi inaugurado em 2003, com a finalidade de atender a uma demanda reprimida de vagas em Santa Catarina. Essa unidade de segurança máxima passou a abrigar os detentos com maior grau de periculosidade do estado, além de detentos vindos de outros estados. Com capacidade para 1.056 presos, atendidos por 150 agentes penitenciários, desde o início a unidade já ultrapassava esse limite, abrigando até 1.190 detentos exclusivamente do gênero masculino².

A gestão da organização, historicamente ocupada por policiais militares e civis já aposentados (da reserva) ou por pessoas indicadas politicamente, foi marcada por denúncias de improbidade administrativa, negligência e maus-tratos aos internos. A crise institucional coadunou com o reconhecimento da categoria de agentes penitenciários, em uma função distinta das polícias e subordinada a uma secretaria própria, a Secretaria de Justiça e Cidadania (SJC). Com isso, as unidades prisionais do estado passaram a gerir os recursos provenientes do Fundo Penitenciário (FUPEN) e a categoria profissional fortalecida passou a ocupar os cargos de gestão nas unidades prisionais.

A mudança no perfil de gestão estabeleceu novas práticas de trabalho baseadas na experiência desses profissionais, sobretudo no enfrentamento do crime organizado. Em 2010, um dos primeiros agentes a ocupar o posto de gestor assumiu a unidade após uma crise institucional e denúncias ao MP, que envolviam casos de tortura e improbidade administrativa.

Além da crise institucional, a massa carcerária era coordenada por um grupo criminoso articulado e fortalecido com alto poder de influência. O Primeiro Grupo Catarinense (PGC) se formou a partir da junção dos detentos de maior periculosidade do estado, que foram transferidos para aquele complexo a partir de 2003. 0 grupo se valeu da gestão negligente dos anos anteriores e da corrupção de alguns agentes penitenciários para criar suas próprias regras e obter privilégios dentro da unidade. O PGC passou a se impor aos detentos de outras facções oriundas do Rio de Janeiro e de São Paulo na disputa por membros e pelo tráfico de drogas tanto dentro como fora das prisões.

A disputa entre diferentes faç̧ões resultou em aumento do número de mortes dentro da unidade e, posteriormente, em uma crise de segurança pública sem precedentes em todo o estado catarinense, a partir de ondas de violência urbana nos anos de 2012, 2013 e $2014 .^{3}$

A mudança nas práticas de gestão no COPE está relacionadas a esses eventos e neste estudo elas constituem evidências do fenômeno em análise.

Nas seções seguintes são descritas as principais práticas mapeadas nesta pesquisa, que singularizam esse tipo de organização: a) "a chave"; b) os uniformes; c) os cigarros; d) as visitas; e) as galerias; f) as transferências; g) o trabalho dos detentos; e h) a assistência à saúde.

\section{O "trabalho na chave" e a chave da cadeia}

Embora as prisões no Brasil possam ser vistas como instituições racionais e planejadas, como máquinas construídas para atingir objetivos oficialmente determinados e aprovados, sua missão é, no mínimo, contraditória: a punição/segregação dos condenados e, concomitantemente, a sua segurança e recuperação. As práticas cotidianas nessas organizações espelham tais contradições, o que intensifica a contingência inerente aos grupos humanos sobre os quais opera (GIRIN, 1996, 2011; GOFFMAN, 2001, 2008).

As práticas de trabalho dos agentes poderiam resumir-se a um quadro de atividades previamente descrito e estabelecido na caracterização do cargo, sobre as quais o agente, em sua rotina, administra as tarefas respeitando uma sequência a ser executada. Isso faria sentido caso fosse validado o pressuposto do planejamento e da execução racionais diante de uma demanda previsível. Todavia, os agentes atuam sobre um conjunto de situações complexas que envolve os anseios, as necessidades dos indivíduos ali encarcerados, com todos os riscos emocionais, psíquicos e mesmo físicos que uma instituição dessa natureza pode acarretar tanto aos confinados quanto aos trabalhadores do sistema.

\footnotetext{
${ }^{2}$ Dados do relatório do INFOPEN do Ministério da Justiça/Departamento Penitenciário Nacional - Depen (BRASIL, 2017).

${ }^{3}$ As três crises consecutivas na segurança pública no estado de Santa Catarina foram coordenadas pela ação da facção criminosa PGC, facção que se formou no interior do complexo penitenciário de segurança máxima do Estado. De dentro da unidade partiram as ordens para mais de 100 atentados em 33 cidades do Estado, foram 37 ônibus queimados e uma série de atos violentos nas ruas (CAITANO, 2016).
} 
O "trabalho na chave" - expressão utilizada pelos agentes do COPE para caracterizar as atividades dos agentes que trabalham diretamente com os internos - diz respeito à abertura, ao acompanhamento e ao fechamento das celas com o consequente acompanhamento da movimentação diária dos detentos. Esse abrir de portas e o bater do cadeado (simbolizando o efeito sonoro do trabalho na chave), enquanto tarefa corriqueira dos agentes, repete-se diariamente, muitas vezes sem aparentes dificuldades; entretanto, ao "bater a chave", o agente pode deparar-se com uma grave contingência, tal como um preso ferido (ou até assassinado), uma briga entre detentos ou, ainda, uma agressão ao próprio agente.

As contingências relacionadas ao trabalho dos agentes no COPE foram agravadas com o aumento do crime organizado na unidade. O grupo criminoso autodenominado PGC impunha à Direção da Unidade os agentes que poderiam "trabalhar na chave", coibindo a presença de agentes que tentassem fazer cumprir as regras, realizando as revistas adequadamente, apreendendo drogas e objetos de potencial risco.

Os agentes se referiam ao período de crise com a seguinte expressão: "a chave da cadeia estava nas mãos dos presos". As ações de gestão objetivando a retomada do controle que ocorrem a partir de 2011 constituem o pano de fundo das práticas analisadas nas seções seguintes e estiveram diretamente relacionadas às crises levadas para as ruas que se sucederam nos anos posteriores.

\section{Vestuário e cigarros enquanto elementos não humanos do poder simbólico e econômico}

Até o ano de 2010, o governo do estado não fornecia uniforme e equipamentos de segurança, com exceção das armas, aos agentes, assim como uniformes aos presos. Os agentes adquiriam coletes, roupas pretas e coturnos com seus próprios recursos. A busca dos agentes por segurança estava imbricada ao objetivo simbólico de personificação: representar claramente no presídio (em especial no grande pátio) quem é o agente e quem é o preso; na contingência de uma rebelião, facilitar a distinção rápida entre agentes e presos (PICKERING, 2013, 2015). Entre a população encarcerada, a ausência do uniforme viabilizava a diferenciação de status: o poder era simbolizado pelo uso de "roupas de marca" pelos internos:

\section{[...] o preso ostentava roupas caras, um tênis de marca, você olhava e já sabia que o cara tinha influência} ali. (Entrevistado 9)

Já a proibição da entrada de cigarros tocava um aspecto cultural e econômico na cadeia.

Tinha a história entre os agentes de que se tirasse o cigarro, a cadeia caía. (Entrevistado 9)

A lei que proíbe o consumo de cigarro em ambientes fechados passou a vigorar no estado em 2009, porém, dentro da unidade prisional a determinação não era cumprida e havia, por parte dos agentes, certo temor de que a retirada do cigarro ocasionaria grande revolta.

A retirada do cigarro foi um meio importante para fragilizar o poder econômico, uma vez que o cigarro fomentava um "negócio local", supervalorizado por aqueles que detinham poder. A proibição surgiu de forma progressiva, reduzindo as quantidades permitidas até a retirada total e esse processo arrefeceu o impacto no complexo; de qualquer sorte, os detentos que se valiam do comércio do cigarro para exigir favores tiveram seus interesses diretamente contrariados.

A ação da gestão - agora exercida por agentes penitenciários - sobre determinados elementos não humanos, visando a atingir o poder econômico e político das facções, por meio da redução de seu poder simbólico, revela muito além da obediência à lei: indica o conhecimento obtido pela experiência no cotidiano do presídio. A sensibilidade de eliminar gradualmente o uso do cigarro também revela um conhecimento advindo da mesma fonte. Evidencia-se, portanto, a phrónesis, a sabedoria prática como base das ações de gestão diante de situações adversas que se mantinham mediante práticas cristalizadas ao longo do tempo.

\section{As visitas: o elo com o mundo externo e o termômetro da cadeia}

As visitas representam um importante termômetro do clima na prisão. Uma forte evidência disso é que os familiares são orientados pelos detentos a não comparecer às visitas quando há ameaça de rebelião ou um levante iminente. A família tem um contato bastante limitado, reduzido a um número de visitas quinzenais, aguardadas ansiosamente pelos detentos. Por isso, a ausência das visitas na cadeia não é uma circunstância alheia à atenção dos agentes, geralmente está relacionada a uma possível rebelião (GIRIN, 1996, 2011; QUÉRÉ, 1997). 
Os familiares assumem um papel essencial na dinâmica do crime organizado, pois podem ampliar sobremaneira a rede de comunicação além dos muros e não é possível saber ao certo a dimensão de tal rede. 0 que se observa é que os visitantes tornam possível a atuação das facções de dentro para fora das prisões, até em unidades geograficamente distantes. Nesse sentido, a dimensão territorial e espacial tem um papel preponderante e demonstra que o curso das ações nem sempre pode ser determinado com antecedência, mas as ações se materializam na situação em si (QUÉRÉ, 1997; RAULET-COSSET, 2008).

Nesse sentido, a evidência da phrónesis foi percebida no avanço dos trabalhos de inteligência dentro da própria unidade, que aproximaram agentes penitenciários e as polícias civil e militar. Embora não exista um sistema apropriado para interligar a comunicação entre esses serviços, muitas vezes o contato ocorre em grupos de WhatsApp que integram policiais e agentes e viabilizam a comunicação e a troca de informações captadas dentro e fora da prisão. A noção de tempo oportuno, nesse caso, prevalece sobre os mecanismos formais de comunicação e possibilita que os agentes atuem de modo preventivo ao lidarem com planos de rebelião, fugas ou ameaças de morte.

\section{Cada galeria, uma sentença}

A separação dos internos por tempo de reclusão em diferentes galerias foi uma importante medida de gestão adotada no período em questão. Anteriormente, os apenados com tempo reduzido de condenação dividiam as celas com presos sentenciados a 20 ou 30 anos de reclusão. Essa alocação de modo desordenado favorecia o contato entre os presos de maior periculosidade com apenados que já estavam em regime semiaberto ou com permissão para saídas temporárias, isto é, presos que já estavam com "um pé fora da cadeia"4.

A desordem na distribuição dos internos fomentava o crescimento das facções, as quais passaram a disputar a adesão dos detentos:

[...] eram muitos presos entrando para a facção, comecei a ver pela condenação [...] o problema está aí, pegar um cara que tem condenação baixa e colocar com quem tem mais de 100 anos (Entrevistado 1).

Todavia, a realocação esbarrava em um fator limitante: a falta de vagas adequadas para regimes diferenciados:

[...] o preso estava em regime fechado, progride com o semiaberto, mas não tem espaço, então permanecia no regime fechado até abrir uma vaga (Entrevistado 2).

O esforço dos agentes para separarem os presos entre as galerias por tempo de condenação e também por alguns tipos de condenação gerou uma grande movimentação em 2011, registrada nos documentos internos. Na percepção do ex-gestor da unidade, essa mudança enfraqueceu o movimento da facção:

\section{[...] o detento com saída temporária sofria a coação do grupo para cumprir ordens, sob ameaça de ser executado no seu retorno (Entrevistado 1).}

Desobrigado desse "apoio aos irmãos de cela" - expressão empregada no presídio -, o detento poderia considerar as vantagens de não se envolver com o grupo organizado.

Apesar de poder ser considerada óbvia a necessidade de separação por tempo de reclusão, constata-se que tal medida foi tomada somente após ser exercida a gestão do presídio por agentes penitenciários. O processo de deliberar as alocações não dependeu da ampliação da estrutura, mas da experiência dos agentes para mobilizar os detentos a partir do tempo de condenação.

A experiência no COPE também levou os gestores do sistema penal no estado a abandonarem os projetos de grandes complexos prisionais, por favorecerem a concentração de detentos de alta periculosidade e a proliferação do crime organizado. Por conseguinte, as unidades prisionais mais recentes no estado são projetadas com capacidade máxima de 300 internos, já contam com os espaços de trabalho apropriados e seguros e, além disso, Santa Catarina passou a investir na implantação de tornozeleiras eletrônicas ${ }^{5}$.

\footnotetext{
${ }^{4}$ Jargão utilizado para indicar os detentos que em pouco tempo terminarão de cumprir sua pena.

${ }^{5}$ Até dezembro de 2019 já foram instaladas 1150 tornozeleiras de monitoramento eletrônico em todo o estado.
} 


\section{A transferência interna de detentos}

No ano de 2011 foram registradas 11 mortes em apenas 5 meses, o que levou o MP e o Conselho Nacional de Justiça (CNJ) a intervir na unidade para investigar as causas. Pelo menos em 8 casos foi comprovado que se tratava de brigas entre facções rivais, o que levou os agentes a modificarem as práticas das transferências entre galerias e celas. Cada transferência passou a ser analisada caso a caso, com as afiliações aos grupos mapeadas e registradas no sistema de informações penais (IPEN), informações decisivas nas transferências.

As movimentações fazem parte da dinâmica do trabalho na prisão, um processo sistemático que não envolvia a análise do registro do interno. Porém, o que os agentes percebiam é que os pedidos de transferência eram minuciosamente articulados entre os líderes criminosos com intuito de enviar mensagens, angariar novos membros para o grupo ou cumprir mandados de execução entre os detentos; tais desvios foram interrompidos com a retomada do controle das movimentações pelos agentes.

Como explica um agente:

[...] o convívio dentro de uma cela pode se tornar insustentável, um desentendimento qualquer pode inviabilizar o convívio entre os detentos. É preciso que os detentos de outra cela aceitem o convívio pacífico com aquele detento que chega (Entrevistado 3).

A questão que pesa sobre os agentes é a responsabilidade prevista em lei sobre a segurança e a vida do apenado. Deliberar transferências em situações que envolvem a ameaça, por exemplo, em uma situação que o detento se recusava a retornar para a cela:

[...] se eu deixar o detento na cela e ele amanhecer morto [...] mas também posso mudar ele de cela e se ele for lá pra cumprir uma ordem e matar outro preso? (Entrevistado 4).

Nesses casos, o que se observou é que o sujeito, em um momento de desespero, ameaçado quanto à sua própria segurança, pode reagir de modo inusitado. Esse tipo de situação assume uma forma heterogênea, fruto da combinação de diferentes fatores (QUÉRÉ, 1997). De toda forma, o agente não está individualmente alheio à segurança do interno, porquanto a decisão de manter ou não o detento em determinada cela também põe em questão os valores sobre os quais o agente rege sua própria conduta. No COPE, nessas situações, o agente tem o poder discricionário de deliberar e agir.

O esforço no mapeamento das afiliações dos detentos a grupos específicos e o respectivo registro no sistema compõem um quadro de práticas que foram inseridas e fortalecidas a partir do conhecimento prático advindo da experiência dos agentes. Do mesmo modo, a phrónesis se manifesta (com ainda mais evidência) nas situações em que os agentes passam a ter o poder de deliberar e agir sobre transferência de detentos em situações emergenciais. Em casos emergenciais, o tempo é um elemento determinante sobre a segurança do interno, o agente plantonista e a supervisão do plantão deverão deliberar a partir de seu conhecimento da situação.

\section{O trabalho dos detentos na prisão}

O trabalho na prisão representa, para grande parte dos internos, um benefício: reduz o tempo de condenação e oferece um salário em contrapartida. Por isso, a seleção dos internos para o trabalho nas oficinas de empresas privadas, instaladas no interior do complexo, requer análise criminológica e do perfil psicossocial do interno.

Essa análise é realizada por uma comissão formada por agentes, psicólogos e assistentes sociais, selecionando os detentos aptos para o trabalho a partir de uma série de critérios objetivos e subjetivos. A oportunidade de trabalho determina, por exemplo, o acesso a áreas externas, à cozinha, além do uso de facas e ferramentas.

Esse tipo de avaliação aos cuidados da equipe recebia a assinatura do parecerista e era despachada para a Justiça Criminal. O processo passou a ser assinado em conjunto, em nome da comissão instituída pela organização ter produzido uma contingência relacionada a esse processo. O parecer desfavorável para um dos internos, assinado por uma psicóloga e anexado ao processo criminal foi motivo de ameaça:

[...] depois que ela negou o pedido, o preso escreveu na parede de uma cela o nome dela e uma ameaça:

"fulana, você vai morrer" (Entrevistado 8). 
A instauração de uma comissão para selecionar e assinar os pareceres à Justiça diluiu o risco dos profissionais que assinavam tais pareceres. A criação do comitê emerge da experiência e sabedoria prática dos agentes, mediante a situação de vulnerabilidade que foi constatada na ameaça à psicóloga.

Entre os internos que trabalham também há aqueles que prestam serviços para a própria unidade prisional, chamados de "regalias". Esses detentos assumem atividades na cozinha, na enfermaria, na limpeza, na manutenção etc. No âmbito da relação interpessoal cotidiana entre o agente e o detento, a posição de um "regalia" é percebida pelos agentes como de confiança.

No relato de um agente, explica-se a complexidade dessa relação de confiança relacionando-a ao passado do detento, à autenticidade deste, e aos valores morais do agente:

\section{[...] eu sempre digo para os agentes não perguntarem por qual artigo eles foram condenados, dependendo} do crime, eles mentem e quebram a confiança (Entrevistado 11).

Na prática, há uma espécie de ajustamento de convivência entre os agentes e os "regalias" em prol da manutenção da unidade.

Ao recomendar que os agentes desconheçam a condenação do interno, o agente, com mais de 20 anos de experiência, demonstra uma clara deliberação embasada na phrónesis. Na percepção do entrevistado, esse conhecimento coloca o agente em confronto com os valores morais e gera um julgamento, portanto, um choque entre a racionalidade e a ação necessária.

No limite das racionalidades em confronto, a sabedoria prática se torna uma via de superação do impasse, embasando a deliberação da ação e instituindo novas práticas, tais como a instalação da comissão e a manutenção da relação de confiança com os "regalias".

\section{A escolta hospitalar e judicial}

Os detentos são escoltados sempre que há uma emergência médica ou quando devem comparecer ao fórum para julgamento. As escoltas para o fórum foram reduzidas com a implantação das audiências por videoconferência, a expectativa é de que todos os julgamentos sejam progressivamente realizados por vídeo. Porém, as demandas de saúde ainda envolvem situações contingenciais, como surtos psicóticos, tentativas de suicídio, mutilações ou condições que requerem internação.

A unidade possui uma ala de atendimento ambulatorial, porém, em casos graves o detento é encaminhado ao hospital na companhia permanente de um agente. A imprevisibilidade dessas ocorrências envolve o risco de morte dos encarcerados e a responsabilização do agente pela segurança externa do condenado. Aqui reside uma evidência da contradição que caracteriza a missão do agente penitenciário, para a qual já chamamos a atenção: a punição/segregação dos condenados e, concomitantemente, a segurança.

O registro de uma tentativa de suicídio no relatório de plantão foi objeto de nossa atenção; o agente que conduziu a situação externou sua indignação:

[...] tive que levar ele pra fazer exame de corpo delito e registrar BO na delegacia. Na volta, no carro, o cara tirou um pedaço de gilete da calça e tentou se matar de novo (Entrevistado 4).

Esse fato ilustra as dificuldades da equipe de trabalho que opera diretamente sobre situações contingenciais e demandas emocionais, psíquicas, biológicas dos internos (GIRIN, 1996, 2011; GOFFMAN, 2001). O trabalho envolve a contenção das inúmeras tentativas de suicídio dos internos e a manutenção de um padrão humanitário de atendimento (GOFFMAN, 2001, 2008).

Um recurso adotado nos últimos anos na Unidade foi o uso de câmeras, que partiu da percepção prática dos agentes da vulnerabilidade desses casos, com possibilidade do agente ser penalizado e responsabilizado pela morte do detento. Em casos envolvendo emergências psiquiátricas, a situação é ainda mais grave, visto que os internos tendem a resistir à medicação ou à condução ao atendimento hospitalar. 


\section{EVIDÊNCIAS DA PHRÓNESIS: UMA SAÍDA NA AÇÃO PARA OS LIMITES DA RAZÃo}

A experiência prática vivenciada pelos agentes penitenciários no enfrentamento do crime organizado tipifica um fenômeno totalmente relacionado ao contexto onde se insere a organização e seus agentes. O crime organizado e os mecanismos de articulação desses grupos fazem parte de um conjunto de fenômenos organizacionais negligenciados sob o ponto de vista científico da gestão, pois não há estudos que auxiliem a compreensão de seus processos. Na medida em que as contingências relacionadas às penitenciárias se amplificam, a ponto de impactarem a segurança coletiva, o fenômeno assume o caráter de um problema público (GIRIN, 1996, 2011; CEFAï, 2009; DIAS, 2011).

A experiência vivenciada pelos agentes penitenciários na gestão da unidade prisional aqui analisada demonstrou diversas práticas, ações e saberes desenvolvidos por eles e que foram necessariamente incorporadas à práxis organizacional. Na avaliação dos agentes, os mecanismos que o crime organizado mobiliza para disputar o poder dentro de uma prisão envolvem uma série de microdinâmicas encobertas sob a perspectiva da gestão. Como relatou um dos agentes:

[...] a pequena parcela de detentos que coloca uma cadeia abaixo não está brigando por direitos, mas está disputando a entrada de drogas, a morte de membros, a transferência dos líderes para unidades federais (Entrevistado 3).

Esse enfrentamento diário em situações críticas expressa os elementos da phrónesis:

- A contingência da situação, o momento adequado de agir (tempo oportuno) e o cálculo e o deliberar sobre as consequências (ARISTÓTELES, 1991; AUBENQUE, 2008).

Esses elementos caracterizam o trabalho prisional como uma atividade prudencial, que envolve a ação deliberada sobre um universo de contingências (FLYVBJERG, 2001, 2006; CHAMPY, 2018; DUBOIS, 2018).

O saber prático se manifesta nas deliberações sobre situações rotineiras como retomada do controle via ações simbólicas graduais, bem como em situações críticas, nas quais o agente passa a ter autonomia para deliberar, estabelecendo o cálculo das consequências e julgando possibilidades de alta gravidade, por exemplo, o risco de morte de um detento ou o risco da movimentação entre as celas. O que a análise do fenômeno tem a destacar é a incorporação/institucionalização dessa sabedoria prática, portanto, da phrónesis, nas ações de gestão, muitas das quais pressionadas por racionalidades opostas.

Nesse sentido, o agente delibera a partir de sua percepção prática do fato, de modo calculado e no momento adequado, sobre um fato contingencial. Portanto, o deliberar dessa ação não está pautado no conhecimento científico ou, ainda, burocrático que advém das regras, das instruções e dos procedimentos, mas a partir da phrónesis (FLYVBJERG, 2006; AUBENQUE; 2008). O Quadro 2 traz uma síntese de situações analisadas que compõe um quadro de evidências da contingência situacional, o tempo oportuno para ação, o deliberar e o agir incorporado nas práticas de gestão adotadas pelos agentes penitenciários enquanto novos gestores do COPE. 


\section{Quadro 2}

\section{Evidências da phrónesis: situações identificadas}

\begin{tabular}{|c|c|}
\hline $\begin{array}{c}\text { TEMPO OPORTUNO } \\
\text { PARA AÇÃO }\end{array}$ & $\begin{array}{l}\text { A formação de grupos criminosos } \\
\text { Disputas de membros entre facções } \\
\text { Controle sobre decisões importantes no presídio } \\
\text { Homicídios e tentativas de homicídio } \\
\text { Fluxo de informações de dentro para fora do presídio } \\
\text { Transferências de cela motivadas por acertos de conta } \\
\text { Suicídio e tentativas de suicídio } \\
\text { Emergências médicas e atendimento hospitalar }\end{array}$ \\
\hline $\begin{array}{c}\text { DELIBERAÇÃO COM BASE } \\
\text { NA PHRÓNESIS } \\
\text { ESCOLHA/CONSEQUÊNCIAS }\end{array}$ & $\begin{array}{l}\text { Separação por tempo de reclusão em diferentes galerias } \\
\text { Oportunidades de trabalho para os detentos } \\
\text { Transferências de cela } \\
\text { Proibição do consumo de cigarros } \\
\text { Implantação dos uniformes } \\
\text { Oportunidades de trabalho nas oficinas } \\
\text { Oportunidade de trabalho como "regalia" }\end{array}$ \\
\hline
\end{tabular}

Fonte: Elaborado pelos autores.

Em suma, as evidências levantadas neste estudo possibilitam demonstrar como a phrónesis representa para a gestão tanto uma alternativa à unilateralidade da ação racional instrumental quanto, principalmente, a forma de superar os dilemas e as tensões vivenciados(as) pelo choque de racionalidades no contexto de um mundo contingente.

\section{CONSIDERAÇÕES FINAIS}

A noção de phrónesis ilumina o entendimento das práticas de gestão das organizações confinadas e subjugadas pelos limites da racionalidade instrumental (CLEGG, 2003, 2006; AUBENQUE, 2008). As teorias da administração, caracterizadas pela busca incessante da prescrição, da normatização e da previsão, não estão devidamente preparadas para abarcar o universo de fenômenos relacionados aos sujeitos e às incertezas do contingente relativo às organizações (FLYVBJERG, 2001, 2006).

A partir da análise do caso em questão, pode-se inferir que a ação humana nas organizações, incluindo a gestão, manifesta complexos processos de entrelaçamento de racionalidades, sendo a sabedoria prática, ou phrónesis, uma disposição racional mediadora de tal entrelaçamento. Portanto, na dinâmica da gestão de um complexo prisional, foram identificados elementos que desvelam essa complexidade, bem como, expressam os elementos da phrónesis nas contingências e na ação deliberada, a partir das situações de gestão nas quais o conhecimento técnico ou científico disponível se mostra claramente insuficiente.

O que constatamos neste estudo é que toda a experiência de gestão dos agentes penitenciários que atuaram nas crises de enfrentamento ao crime organizado constituiu um saber próprio, inerente à experiência dessa categoria profissional. Esse conhecimento indica evidências da phrónesis, um saber prático que advém da experiência dos atores (FLYVJBERG, 2001, 2006; BOLTANSKI e THÉVENOT, 2006; AUBENQUE, 2008; FREGA, 2006, 2012).

A experiência desses agentes diante dos eventos críticos que se sucederam com o crescimento das disputas entre faç̧ões dentro da unidade produziu uma série de medidas de gestão iniciadas a partir daquela unidade. 0 sistema prisional de Santa Catarina e suas práticas de gestão geradas no COPE são alvo, hoje, do interesse de várias outras unidades da Federação ${ }^{6}$. Muitas das iniciativas positivas partiram da percepção dos agentes daquela Unidade, a primeira a adotar a gestão exercida pelos próprios profissionais da categoria.

${ }^{6} \mathrm{O}$ sistema prisional do estado de Santa Catarina é considerado referência no Brasil em número de presos que trabalham. O estado foi escolhido pelo Ministério da Justiça como sede da primeira e segunda Mostra Laboral do Sistema Prisional Brasileiro, nos anos de 2017 e 2018 respectivamente. 
As contingências relacionadas ao trabalho dos agentes no complexo de segurança máxima produziram efeitos na gestão e mudanças nas práticas de trabalho, também fortalecendo a categoria profissional que hoje é majoritariamente gestora das unidades prisionais de todo o estado. Como reflexo desse esforço e da capacidade profissional desses agentes, o nomeado para o cargo de Secretário de Justiça e Cidadania é um agente penitenciário de carreira.

A experiência desses profissionais, antes limitada ao trabalho operacional, passou a ser legitimada com base na gestão em período de crise. As novas práticas de gestão mapeadas neste estudo permaneceram e novas práticas têm sido instauradas a partir da perspectiva e do conhecimento advindo da experiência dos agentes. Hoje, a antiga escola penal de formação é a Academia de Administração Prisional e Socioeducativa (ACAPS) e oferece programas de capacitação e treinamento específicos para o trabalho prisional, tais como práticas regulares, atuação em situações críticas, intervenção prisional e simulação de rebeliões.

A experiência prática dos agentes que reformularam a gestão e enfrentaram as crises no período passa a se institucionalizar como um conhecimento técnico instrucional. A partir da ACAPS já se constituíram grupos táticos de intervenção, os quais passaram a atender a demandas de penitenciárias federais e de outros estados na contenção de megarrebeliões.

Da imersão nas práticas e nas ações dos sujeitos, diante do ambiente adverso herdado de gestões anteriores e dos momentos críticos vividos no presente, sobressai o entendimento de que uma maior compreensão acerca da racionalidade na gestão poderia estacionar no campo conceitual da abstração teórica e da análise restrita ao mapeamento dos valores morais do indivíduo. As evidências aqui identificadas nos levam a crer que, se desejamos ampliar o conhecimento da racionalidade na gestão, notadamente no limite complexo e altamente sensível onde o sujeito pode tomar suas decisões de modo racional, nossos esforços devem concentrar-se na análise da ação (FLYVBJERG, 2006; CLEGG, 2006).

Por fim, no que tange à discussão teórica que mobilizou esta investigação, concluímos: ainda que o sujeito pondere acerca de uma lógica racional instrumental ou substantiva, é no campo da ação que esses aspectos podem ser compreendidos, propiciando contribuições efetivas ao avanço da administração como ciência social aplicada.

Este ponto caracteriza o que neste estudo se compreende como o "limite da razão". 


\section{REFERÊNCIAS}

ADORNO, S. Exclusão socioeconômica e violência urbana. Sociologias, v. 4, n. 8, p. 84-135, 2002.

ADORNO, S. Políticas públicas de segurança e Justiça Penal. Cadernos Adenauer, v. 9, n. 4, p. 9-27, 2008.

ARISTÓTELES. Ética a Nicômaco: Poética. 4. ed. São Paulo: Nova Cultural, 1991.

AUBENQUE, P. A prudência em Aristóteles. São Paulo: Discurso Editorial, 2008.

BODÊ DE MORAES, P. R. Punição, encarceramento e construção de identidade profissional entre agentes penitenciários. São Paulo: Instituto Brasileiro de Ciências Criminais, 2005.

BODÊ DE MORAES, P. A identidade e o papel de agentes penitenciários. Tempo Social, v. 25, n. 1, p. 131-147, 1 jun. 2013.

BOLTANSKI, L.; THÉVENOT, L. On justification: economies of worth. Princeton, NJ: Princeton University Press, 2006.

BRASIL. Departamento Penitenciário Nacional - DEPEN. Sistema de Informações do Departamento Penitenciário Nacional SISDEPEN: População carcerária. 2017. Disponível em: <http:// depen.gov.br/DEPEN/depen/sisdepen/infopen/relatorios-analiticos/ SC/sc>. Acesso em: 05 fev. 2020.

CAITANO, D. I. M. O. No Limite da Razão: a tensão, o deliberar e phronesis. Uma análise pragmática sobre situações críticas de gestão no trabalho dos agentes no complexo penitenciário do estado (COPE). 2016. Tese (Doutorado em Administração) - Universidade Federal de Santa Catarina, Centro Socioeconômico, Florianópolis, 2016.

CEFAï, D. Como nos mobilizamos? A contribuição de uma abordagem pragmatista para a sociologia da ação coletiva. Dilemas - Revista de Estudos de Conflito e Controle Social, v. 2, n. 4, p. 11-48. 2009.

CLEGG, S. Organizations: Power/History/Imagination. Cadernos EBAPE.BR, Rio de Janeiro, v. 1, n. 1, p. 22 a 34, jan. 2003.

CLEGG, S. The bounds of rationality: power/history/imagination. Critical Perspectives on Accounting, v. 17, n. 7. 2006, p. 847-863.

CABRAL, S.; LAZZARINI, S. G. Impactos da participação privada no sistema prisional: evidências a partir da terceirização de prisões no Paraná. Revista Administração Contemporânea, Curitiba, v. 14, n. 3, p. 395-413, maio/jun. 2010.

CHAMPY, F. The sociology of prudential activities: from collective commitment to social inovations. Sociologia, problemas e práticas, n. 88, p. 79-94, 2018.

CRUZ, M. V. G.; SOUZA, L. G.; BATITUCCI, E. C. Percurso recente da política penitenciária no Brasil: o caso de São Paulo. Revista de Administração Pública, Rio de Janeiro, v. 47, n. 5, p. 1307-1325, out. 2013.

DIAS, C. N. Estado e PCC em meio às tramas do poder arbitrário nas prisões. Tempo Social, v. 23, n. 2, p. 213-233, 2011.

DODIER, N. L'espace et le mouvement du sens critique. Annales HSS, v. 60, n. 1, p. 7-31, 2005.

DUBOIS, C. Prison Governors as Policymakers, Phronetic Practices as Enacted Knowledge. The Howard Journal of crime and justice, v. 57, n. 3, p. 363-378, set. 2018.
ESCUDERO, J. A. Heidegger, lector de la retórica aristotélica. Diánoia, v. 56, n. 66, p. 3-29, 2011.

FLYVBJERG, B. Rationality and power: democracy in practice. Chicago: University of Chicago Press, 1998.

FLYVBJERG, B. Making social science matter: why social inquiry fails and how it can succeed again. Cambridge: Cambridge University Press, 2001.

FLYVBJERG, B. Making organization research matter: power, values, and phrónesis. In: CZARNIAWSKA, B.; SEVÓN, G. (Ed.). The Northern lights: organization theory in Scandinavia. Stockholm: Liber, 2003. p. 370-387.

FLYVBJERG, B. Making Organization Research Matter: Power, Values, and Phrónesis. In: CLEGG, S. R. et al. (Eds.). The Sage Handbook of Organization Studies. 2. ed. Thousand Oaks: Sage, 2006. p. 370-387.

FÓRUM BRASILEIRO DE SEGURANÇA PÚBLICA - FBSP. Anuário Brasileiro de Segurança Pública 2013. 7. ed. São Paulo: FBSP, 2015.

FREGA, R. John Dewey et la philosophie comme épistémologie de la pratique. Paris: L'Harmattan, 2006.

FREGA, R. Practice, judgment, and the challenge of moral and political disagreement: a pragmatist account. Lanham: Lexington, 2012.

FREITAS, R. Reversões hierárquicas e eclosão de conflitos em prisões. Revista de Administração Pública, Rio de Janeiro, v. 19, n. 4, p. 27-37, 1985.

GIRIN, J. A linguagem nas organizações: signos e símbolos. In: CHANLAT, J. F. (Coord.). $O$ indivíduo na organização: dimensões esquecidas. São Paulo: Atlas, 1996. v. 3. p. 23-66.

GIRIN, J. Empirical Analysis of Management Situations: Elements of Theory and Method. European Management Review, v. 8, n. 4. p. 197-212, 2011.

GOFFMAN, E. Manicômios, prisões e conventos. São Paulo: Perspectiva, 2001.

GOFFMAN, E. Estigma: notas sobre a manipulação da identidade deteriorada. Rio de Janeiro: LTC, 2008.

GUERREIRO RAMOS, A. A nova ciência das organizações: uma reconceituação da riqueza das nações. Rio de Janeiro: Ed. FGV, 1989.

KARAM, C. A. Legitimando uma inovação social: o caso do corpo de bombeiros voluntários de Joinville. Tese (Doutorado em Administração) - Universidade Federal de Santa Catarina, Centro Socioeconômico, Florianópolis, 2014.

KOIKE, K.; MATTOS, P. L. C. L. Entre a epistêmê e a phrónesis: antigas lições para a moderna aprendizagem em administração. Perspectiva Filosófica, v. 7, n. 13, p. 179-193, 2001.

LEMOS, A. M.; MAZZILLI, C.; KLERING, L. R. Análise do Trabalho Prisional: um Estudo Exploratório. Revista de Administração Contemporânea, v.2, n.3, p. 129-149, set./dez. 1998.

LIMA, R. S.; BUENO, S. Introdução: o eterno presente da segurança pública brasileira. In: FÓRUM BRASILEIRO DE SEGURANÇA PÚBLICA 
- FBSP. Anuário Brasileiro de Segurança Pública 2015. 9. ed. São Paulo: FBSP, 2015. p. 8-9.

MACINTYRE, A. Justiça de quem? Qual racionalidade? São Paulo: Loyola, 1991.

MANSO, B.P.; DIAS, C. N. PCC, sistema prisional e gestão do novo mundo do crime no Brasil. Revista brasileira de segurança pública. São Paulo v. 11, n. 2, 10-29, ago./set. 2017.

PICKERING, A. Living in the material world. In: DEVAUJANY, F.; MITEV, N. (Eds.). Materiality and space: organizations, artefacts and practices. London: Macmillan, 2013. p. 25-40.

PICKERING, A. Science, Contingency and Ontology. In: SOLER, L.; TRIZIO, M.; PICKERING, A. (Eds.). Science as It Could Have Been: Discussing the Contingenty/Inevitability Problem. Pittsburgh: University of Pittsburgh Press, 2015. p. 117-28.

QUÉRÉ, L. La situation toujours négligée? Réseaux, n. 85, p. 163192, 1997.

RANGEL, F. M.; BICALHO, P. P. G. Superlotação das prisões brasileiras: Operador político da racionalidade contemporânea. Estudos de Psicologia, Natal, v. 21, n. 4, p. 415-423, 2006. Disponível em: <http:// ref.scielo.org/jrqd6f.> Acesso em: 02 fev. 2020.
RAULET-CROSET. La dimension territoriale des situations de gestion. Revue française de gestion, Lavoisier, n. 184, p. 137-150, 2008.

SALLA, F. As rebeliões nas prisões: novos significados a partir da experiência brasileira. Sociologias, n. 16, p. 274-304, 2006.

SANTOS, L. S. et al. Razão e Administração: revisitando alguns elementos fundamentais. Cadernos EBAPE.BR, Rio de Janeiro, v. 17, n. 1, p. 37-48, dez. 2018.

SERVA, M. A racionalidade substantiva demonstrada na prática administrativa. Revista de Administração de Empresas, v. 37, n. 2 , p. 18-30, 1997a.

SERVA, M. Abordagem substantiva e ação comunicativa: uma complementaridade frutuosa para a teoria das organizações. Revista de Administração Pública, Rio de Janeiro, v. 31, n. 2, p. 108134, 1997b.

SERVA, M. et al. A análise da racionalidade nas organizações: um balanço do desenvolvimento de um campo de estudos no Brasil. Cadernos EBAPE.BR, Rio de Janeiro, v. 13, n. 3, p. 414-437, 2015.

VANDENBERGUE, F. Construção e crítica na nova sociologia francesa. Sociedade e Estado, v. 21, n. 2, p. 315-366, 2006.

Déris Oliveira Caitano

ORCID: https://orcid.org/0000-0002-0284-1546

Doutora em Administração; Pesquisadora do Núcleo de Pesquisa em Organizações, Racionalidade e Desenvolvimento na Universidade Federal de Santa Catarina (ORD/UFSC), Florianópolis - SC, Brasil. E-mail: derisoliveira@gmail.com

Maurício Serva

ORCID: https://orcid.org/0000-0003-2416-3405

Doutor em Administração; Professor da Universidade Federal de Santa Catarina; Coordenador do Núcleo de Pesquisa em Organizações,

Racionalidade e Desenvolvimento na Universidade Federal de Santa Catarina (ORD/UFSC), Florianópolis - SC, Brasil. E-mail: mauserva@gmail.com 